\title{
INFLUENCE OF PHYSICAL FACTORS OF APARTMENTS, EDUCATIONAL ATTAINMENT, NATIONALITY AND UNEMPLOYMENT ON THE NUMBER OF CIMEX LECTULARIUS INQUIRIES
}

\author{
Attila J. Trájer ${ }^{1}$, Tamás Hammer ${ }^{2}$, Zsolt Szigeti ${ }^{3}$ \\ 'Department of Limnology, University of Pannonia, Veszprém, Hungary \\ ${ }^{2}$ Independent Researcher, Veszprém, Hungary \\ ${ }^{3}$ Abatox Ltd., Budapest, Hungary
}

\begin{abstract}
SUMMARY
Objective: The aim of the study was to determine the effect of physical factors of apartments, educational attainment, nationality and unemployment on the number and distribution of bed bug call inquiries in Budapest, Hungary.

Methods: Educational attainment, apartment conditions, the level of unemployment, the ratio of dependent people in the households, nationality and proportion of dependent people were selected as regressors. Monthly ambient temperature values were correlated with monthly call inquiry numbers.

Results: Downtown units showed the highest call inquiry rates. Significant positive correlations were found between the call inquiry rates and the ratio of low educational attainment inhabitants (people with $\leq 8$ school classes), the rate of small floor area apartments (apartment area $<29 \mathrm{~m}^{2}$ ), proportions of the comfortless apartments in the district housing stock and proportion of unemployed people on district level as well as proportion of gypsy inhabitants in the districts. Significant negative correlation was found between the call inquiry rates and the average area $\left(\mathrm{m}^{2}\right)$ of apartments. The number of call inquiries showed expressed, temperature-depending seasonality between March and December 2015. In multiple regression analyses, the level of unemployment and proportion of gypsy inhabitants showed significant correlations with the rate of bed bug call inquiries.

Conclusions: Apartment conditions, educational attainment, nationality, unemployment, and the city structure have notable influence on the occurrence of bed bug call inquiries on urban level, although the level of unemployment and nationality seem to be the strongest factors. The annual changes of the ambient temperature have effect on the call inquiry rate.
\end{abstract}

Key words: Cimex lectularius, apartment conditions, urban distribution, suburb zone, city centre

Address for correspondence: A. J. Trájer, University of Pannonia, Department of Limnology, Egyetem utca 10, H-8200, Veszprém, Hungary. E-mail: attila.trajer@mk.uni-pannon.hu

https://doi.org/10.21101/cejph.a4978

\section{INTRODUCTION}

Cimex lectularius and a close relative Cimex hemipterus are cosmopolite, obligatory hematophagous parasitic members of the cimicid family that feed predominantly on human blood in the manmade environment $(1,2)$. C. lectularius occur around the entire world including temperate areas (3). This species has been known as one of the most notable ectoparasites in the human history (4) occurring already in the ancient Egypt (5). From the second third of the 20th century, due to DDT use, the infestations of $C$. lectularius became rare in the developed world. This situation has changed and the rates of infestations have increased since the 1980 's (6). Insecticide-resistance was already observed among bed bugs in the 1950's (7). After the 1980's, the number of reported infestations showed dramatic increase in the USA and Europe. The resurgence of bed bug infestations was observed e.g. in Zurich, where the dramatic increase of bed bug infestation was observed from the 1990s (8). C. lectularius is a recently re-emerging pest in the developed countries. The resurgence of bed bug infestations in the Northern Hemisphere can be explained by increased international travelling (9), efficiency problems of the new insecticide-free pest-control methods, increased insecticide resistance, more frequent exchange of second-hand furnishings, and certain aspects of socioeconomic trends that occurred in the last decades (10). Now, incidence of bed bugs continues to increase in urban environments throughout the world $(11,12)$. Based on the study of Li et al., both poverty and renting are significant risk factors for bed bug incidence (13). Bed bug infestations cause health problem predominantly in low-income housing communities since ineffective pest management practices are frequently associated with low-income households (14). Especially the multiunit housing buildings are affected where infestations chronically persist serving as dispersal foci of the pest (15). Studying the resurgence of the pest in Canada, Hwang et al. found that bed bugs started appearing in homeless shelters (16). 
Then, it is not surprising that prevalence of bed bug infestations is also associated with resident's socioeconomic status (17) and commonly considered a consequence of poor hygiene and poverty (18). It is also known, that more than half of the worldwide infestations occur in the developing countries (19).

The main impact of the presence of C. lectularius is socioeconomic due to the common belief that poverty and poor hygienic conditions facilitate the emergence of bed bug infestations. In the present study the number of call inquiries on the size and equipment of apartments, education of male and female inhabitants, ratio of dependent people in the households, ratio of gypsy inhabitants, and ratio of unemployed people were monitored in the Hungarian capital, Budapest.

\section{MATERIALS AND METHODS}

\section{Bed Bug Call Inquiry Data}

The data of requests for treatment due to bed bug call inquiries in Budapest were collected from 1st March to 31st December 2015 in the praxis of the Abatox Ltd*. The Abatox Ltd. has been present in pest control for 24 years in Budapest. Every year performs insect (including flea, cockroach, bed bug, wasp, ant, tick) and rodent elimination in more than 10,000 apartments. The total number of call inquiries was 2,812 . The inquiries were registered in all districts (I-XXIII) of Budapest.

The call inquiry rates $\left(\mathrm{R}_{\mathrm{Y}}\right)$ of apartments were calculated according to two following formula:

$$
\begin{aligned}
& R_{I}=\frac{N_{I A}}{N_{T A}} \times 10^{3} \\
& R_{I}=\text { rate of call inquiry } \\
& N_{I A}=\text { number of infested apartments in a given district } \\
& N_{T A}=\text { total number of apartments in a given district }
\end{aligned}
$$

\section{Geographical Processing}

The geographical distribution of bed bug call inquiry rate values was depicted according to the georeferenced localizations of the cases and the $\mathrm{R}_{\mathrm{I}}$ values of the districts. The total number of units was 23,255 . In the graphical presentation the $R_{I}$ data were ordered to the district units in the layer's attribute table. Then, the layers of polygons were coloured according to the ten interval categories of prevalence data in ArcGis 10.0.

\section{Studied Variables}

The following factors were involved in the study:

- educational attainment ( $<8$ class), females;

- average area of apartments $\left(\mathrm{m}^{2}\right)$;

- proportion of small floor area apartments $\left(<29 \mathrm{~m}^{2}\right)$;

- proportion of comfortless apartments (\%);

- proportion of gypsy inhabitants (\%);

- proportion of unemployed people; and

- proportion of dependents (\%).

\footnotetext{
*http://www.abatox.hu - Abatox homepage in Hungarian
}

The educational, employment, nationality and apartment data of the districts were derived from the Hungarian Central Statistical Office (20).

A 'comfortless apartment' has at least one $12 \mathrm{~m}^{2}$ living room and kitchen, and individual (not central) heating mode. The toilet and water supply can be found only outside of the apartment. It has no bathroom and electricity supply.

\section{Ambient Mean Temperature Data}

Monthly mean temperature data were derived from the E-OBS database (21). Average values were calculated from the $0.25^{\circ}$ grid within the domain according to the following limiting coordinates: $47.25-47.75^{\circ} \mathrm{N}$ and $18.75-19.50^{\circ} \mathrm{E}$

\section{Statistics}

Linear regressions were performed by the VassarStats, the multiple regressions analysis was executed by Wessa (2008) free statistical software version 1.1.23-r1. (22, 23). Denomination of the Pearson's correlation coefficients was expressed according to the following categories: $0.00-0.19$ "very weak", $0.20-0.39$ "weak", 0.40-0.59 “moderate", 0.60-0.79 "strong", and 0.80-1.0 "very strong" (24). In the multiple regression equation b1, b2, etc., are the unstandardized regression weights for X1, X2, etc., each analogous to the slope in a simple two-variable regression. The values listed as B are the standardized regression weights.

\section{RESULTS}

\section{General Distribution Patterns}

Most of the bed bug call inquiries were observed in the most populated central parts of Budapest. The most infected areas can be found in the downtown and riverside districts of the capital, mainly in the north-eastern part of the city centre. Further notable call inquiry islands were also observed in the most populated centres of the outer districts of Budapest.

The $0.97 \%$ of the suburb units (143 per 14,702$), 2.27 \%$ of the green condominium units ( 80 per 3,529$), 21.6 \%$ of the closed downtown installation units ( 500 per 2,315 ), and $32.2 \%$ of the residential district units $(875$ per 2,709$)$ were affected by bed bug call inquiries. The mean $\mathrm{R}_{\mathrm{I}}$ value was 295.84 per 1,000 apartments, however, the data show expressly high variation and the distribution is strongly pushed to the left (minimum: 30.81, maximum: 639.39 per 1,000 apartments, median: 170.01; SD: 138.81; histogram: Figure 1).

Excluding two districts (the districts VIII and XV), the $\mathrm{R}_{\mathrm{I}}$ values of the districts were between 30 to 280 per 1,000 apartments. In general, the western part of Budapest, Buda and the peripheral eastern suburb zones appeared to be the less affected areas.

\section{Factors of Spatial Distribution of Bed Bug Call In- quiries}

\section{Linear Regression and Correlation Results}

Educational attainment. We found significant positive correlation (males: $\mathrm{p}=0.0231, \mathrm{r}^{2}=0.2220, \mathrm{~b}=13.313$; females: 


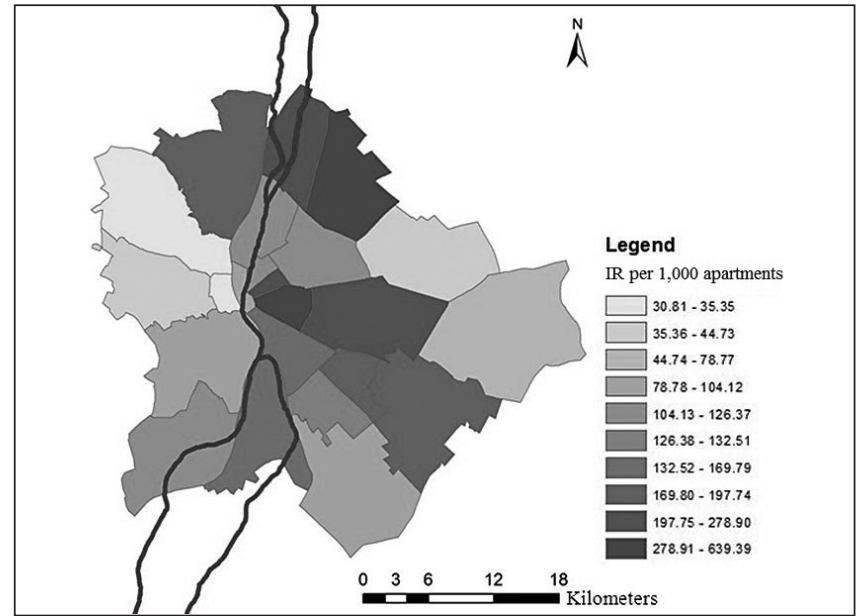

Fig. 1. Bed bug infestation rate values per 1,000 apartments in Budapest on district level (black line: river Danube).

$\left.p=0.0160, r^{2}=0.2462, b=13.380\right)$ between the $R_{I}$ values and the ratios of low educational attained inhabitants (people with maximum 8 elementary classes or less) of the districts.

Housing conditions. Significant negative correlation $\left(p=0.0031, r^{2}=0.3463, b=-13.536\right)$ was found between the $R_{I}$ values and the average area $\left(\mathrm{m}^{2}\right)$ of apartments in the districts. Significant positive correlation $\left(\mathrm{p}=0.0247, \mathrm{r}^{2}=0.2181, \mathrm{~b}=30.882\right.$ ) was found between the $\mathrm{R}_{\mathrm{I}}$ values and the proportion (\%) of small floor area apartments (area $<29 \mathrm{~m}^{2}$ ) in the housing stock of the districts. We found significant positive correlation $(\mathrm{p}=0.0171$, $\left.r^{2}=0.2414, b=142.14\right)$ between the $R_{T}$ values and the proportions (\%) of comfortless households in the housing stock of the districts.

Employment. We found significant positive correlation $\left(\mathrm{p}=0.0010, \mathrm{r}^{2}=0.4074, \mathrm{~b}=63.073\right)$ between the $\mathrm{R}_{\mathrm{I}}$ values and the proportion of unemployed people.

Nationality. Significant positive correlation $(\mathrm{p}=0.3680$, $\left.r^{2}=0.0391, b=-22.916\right)$ was also found between the $R_{I}$ values and the proportion of gypsy inhabitants.

Proportion of dependents. There was no significant correlation $\left(\mathrm{p}<0.0001, \mathrm{r}^{2}=0.5512, \mathrm{~b}=197.81\right)$ found between the $\mathrm{R}_{\mathrm{I}}$ values and the proportion of dependent people in the households.

\section{Multiple Linear Regression Analysis Results}

The multiple linear regression analysis matrix of the variables showed strong negative correlations between the mean area of apartments and any other factors. Strong positive correlations were found between the percentage of comfortless apartments and unemployment, and the percentage of apartments with less than 29 $\mathrm{m}^{2}$ areas. Moderate positive correlations were found between the percentage of comfortless apartments and the percentage of low education attainment and the $\mathrm{R}_{\mathrm{I}}$ values. Very strong correlation was found between unemployment and low educational attainment, as well as between the proportion of comfortless apartments and the proportion of gypsy inhabitants of the districts (Table 1). Unemployment and the proportion of gypsy inhabitants showed significant correlation with the $\mathrm{R}_{\mathrm{I}}$ values (Table 2).

Table 1. Correlation matrix results of multiple linear regression analysis

\begin{tabular}{|l|c|c|c|c|c|c|c|c|c|}
\hline Variable & v1 & v2 & v3 & v4 & v5 & v6 & v7 & v8 & $\mathbf{R}_{\mathbf{l}}$ \\
\hline v1 & 1 & 0.973 & -0.305 & 0.203 & 0.574 & 0.671 & 0.885 & 0.066 & 0.496 \\
\hline v2 & - & 1 & -0.253 & 0.118 & 0.478 & 0.629 & 0.82 & 0.15 & 0.471 \\
\hline v3 & - & - & 1 & -0.702 & -0.484 & -0.599 & -0.355 & 0.571 & -0.588 \\
\hline v4 & - & - & - & 1 & 0.793 & 0.684 & 0.384 & -0.55 & 0.467 \\
\hline v6 & - & - & - & - & 1 & 0.885 & 0.753 & -0.212 & 0.491 \\
\hline v7 & - & - & - & - & - & 1 & 0.826 & -0.174 & 0.742 \\
\hline V8 & - & - & - & - & - & - & 1 & 0.007 & 0.638 \\
\hline$R_{1}$ & - & - & - & - & - & - & - & - & -0.198 \\
\hline
\end{tabular}

$\mathrm{v} 1$ - educational attainment ( $<8$ class), females; v2 - educational attainment (<8 class), males; $v 3$ - average area of apartments $\left(\mathrm{m}^{2}\right)$; $44-\mathrm{proportion}$ of small floor area apartments $\left(<29 \mathrm{~m}^{2}\right)$; v5 - proportion of comfortless apartments (\%); v6 - proportion of gypsy inhabitants (\%); v7 - proportion of unemployed people; v8 - proportion of dependents (\%)

Table 2. Standard deviation (SD), standardized (B) and unstandardized (b) regression coefficients and significance values ( $p)$ according to multiple linear regression analysis

\begin{tabular}{|l|c|c|c|c|c|}
\hline Variable & SD & B & B x rxy & b & 2-tail p-value \\
\hline Educational attainment $(<8$ class), females & 25.38 & 0.6663 & 0.3307 & 17.9648 & 0.3628 \\
\hline Educational attainment $(<8$ class), males & 22.33 & -0.8111 & -0.3821 & -22.9188 & 0.4906 \\
\hline Average area of apartments $\left(\mathrm{m}^{2}\right)$ & 5.748 & 0.0204 & -0.012 & 0.4682 & 0.3220 \\
\hline Proportion of small floor area apartments $\left(<29 \mathrm{~m}^{2}\right)$ & 25.44 & 0.5724 & 0.2673 & 37.8467 & 0.9362 \\
\hline Proportion of comfortless apartments (\%) & 147.5 & -1.5275 & -0.7506 & -441.8884 & 0.1590 \\
\hline Proportion of gypsy inhabitants (\%) & 122.5 & 1.3547 & 1.0058 & 360.935 & $\mathbf{0}$ \\
\hline Proportion of unemployment (\%) & 42.56 & 0.5323 & 0.3397 & 52.5998 & $\mathbf{0}$ \\
\hline Proportion of dependents (\%) & 21.5 & 0.0913 & -0.0181 & 10.5775 & 0.2368 \\
\hline
\end{tabular}

Statistically significant values are indicated in bold. 


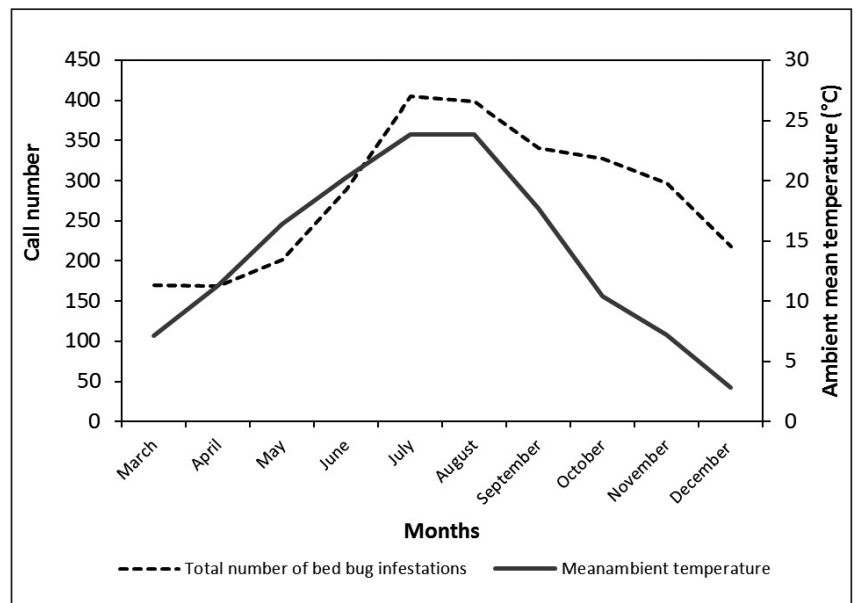

Fig. 2. Total monthly numbers of bed bug call inquiries from 1st March to 31st December 2015 and corresponding monthly temperature values.

\section{Temporal Occurrence of Bed Bug Call Inquiries}

The total number of bed bug call inquiries showed a clear seasonality from 1st March to 31st December 2015. In this period the largest case number was observed in the summer months. Case number showed a rapid increasing trend in spring and June (Fig. 2).

\section{Correlation between Ambient Temperature and Monthly Bed Bug Call Inquiries}

Significant correlation was observed between the monthly mean ambient temperature and the monthly bed bug call inquiries $\left(p=0.0326, r^{2}=0.4543\right)$. The observed part of the year was divided into two periods according to the different profile of correlation between the monthly case number and monthly mean ambient temperature. The case number from March to August (roughly equivalent to the non-heating season) and from September to December (roughly equivalent to the heating season without January and February) showed strong linear correlation with the ambient mean temperature $\left(\mathrm{r}_{\text {III-VIII }}^{2}=0.9978\right.$, equation $2, \mathrm{r}_{\text {IX-XII }}^{2}=0.9989$, equation 3) (Fig. 3).

$N_{\text {cases IX-XII }}=-0.8654 * T_{\text {mean }}^{2}+25.953 * T_{\text {mean }+152.41} \quad$ Eq. 2

$N_{\text {cases I-VIII }}=1.3291 * T_{\text {mean }}^{2}-27.574 * T_{\text {mean }+302.47} \quad$ Eq.3

\section{DISCUSSION}

In Budapest, the downtown and the most populated outside districts have the highest call inquiry levels. The observed spatial pattern of bed bug call inquiries is somewhat asymmetrical since the left side districts (part Pest) are more affected than the right side districts of the city according to the flow direction of the Danube (part Buda). The city structure predominates the spatial occurrence of bed bug occurrence since downtown and closed condominium districts are much more infested than the suburb areas or even the green condominium units. Population density has also influence on the bed bug call inquiry rate; the infestation level of the most populated outer districts is similar to that observed in the

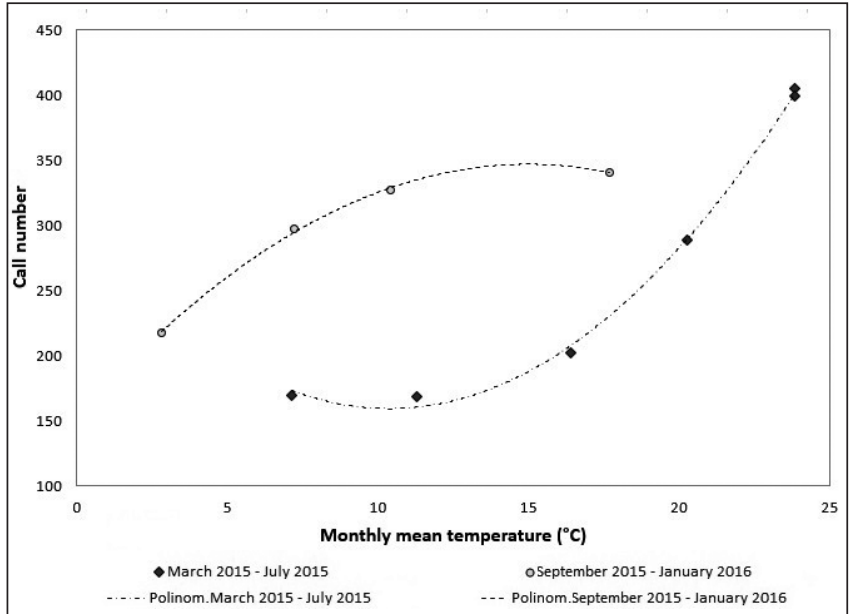

Fig. 3. Correlations between monthly mean ambient temperature and number of cases from 1st March to 31st August and 1 st September to December 2015.

downtown. The studied variables represent the different sides of a complex social phenomenon. We found that the level of unemployment and the proportion of gypsy inhabitants of the districts have strong, significant positive correlation on the spatial occurrence of bed bug call inquiries on urban level. Unemployment and the consequent low socioeconomic status have direct influence on the distribution of bed bug call inquiry rate, although these factors are non-independent variables since e.g. low education attainment is in correlation with harsh housing conditions. Hwang et al. found that bed bug infestations are common among homeless persons living in shelters (25). This may explain the fact why bed bug infestation causes social stigma and is associated with poor hygienic conditions (26). In general, people living in difficult financial circumstances live in worse housing conditions which are clearly visible in the correlation matrix of the multiple regression analysis. Bed bug infestation was always related to poverty in historical times (27). The small interior and overcrowding favour the occurrence since $C$. lectularius can infect easily people in a relatively defined area, e.g. a room or smaller apartment.

The highest number of bed bug call inquiries was observed in July. As it was showed outdoor temperature can play important role in determination of the bed bug infestation season. Alalawi found that bed bug infestation season reaches its peak in August and September, while in January and February, the lowest infestation rate of bed bugs in a year is recorded in the United States (28). Similarly, Mabud et al. also detected prominent seasonality in bed bug reporting, peaking in August and reaching a nadir in February each year (29). The patterns of positive correlation between the number of call inquiries and the ambient temperature from March to August and from September to December showed somewhat different natures. Higher numbers of call inquiries in warmer summer periods may tend to indicate higher activity of people than a sudden increase in bed bugs.

\section{CONCLUSIONS}

It can be concluded that housing conditions, unemployment, educational attainment, and the city structure have notable influ- 
ence on the occurrence of bed bug infestation on urban level. Heating and annual changes in ambient temperature have effect on the number of call inquiries. Due to understanding the environmental requirements of the pest species the spread control of bed bugs within multi-occupancy dwellings can be more successfully performed (30). The poverty-related variables have different strength correlation with the call inquiry rate. Providing education to the affected population who have suspected infestations is indispensable. As it was shown, the risk groups can be well estimated. It is necessary to use professional exterminator services in households to eliminate infestation, however, the eradication of bed bugs from homes can only be achieved by complex social, economic and epidemiological interventions.

\section{Acknowledgement}

We would like to thank to the GeoX Ltd. for their kindness, they made available their gridded data. We also acknowledge the financial support of GINOP-2.3.2-15-2016-00019.

\section{Conflict of Interests}

None declared

\section{Adherence to Ethical Standards}

The bed bug infestation data was diagnosed and collected in the praxis of Abatox Ltd., Hungary. The data were analyzed without information about the identity of individuals. The study was conducted in accordance with the code of the Ethics of the World Medical Association (the Declaration of Helsinki). All analyses were performed on depersonalized, aggregated data. Neither the depicted distribution patterns, nor the aggregated data include any personal information to allow the secondary re-identification of affected apartments or housing communities.

\section{REFERENCES}

1. Bennett GW, Gondhalekar AD, Wang C, Buczkowski G, Gibb TJ. Using research and education to implement practical bed bug control programs in multifamily housing. Pest Manag Sci. 2015;72(1):8-14.

2. Delaunay P, Blanc V, del Giudice P, Levy-Bencheton A, Chosidow $\mathrm{O}$, Marty $\mathrm{P}$, et al. Bedbugs and infectious diseases. Clin Infect Dis. 2011;52(2):200-10.

3. Heukelbach J, Hengge UR. Bed bugs, leeches and hookworm larvae in the skin. Clin Dermatol. 2009;27(3):285-90.

4. Goddard J, de Shazo R. Multiple feeding by the common bed bug, Cimex lectularius, without sensitization. Midsouth Entomol. 2009;2(1):90-2.

5. Panagiotakopulu E, Buckland PC. Cimex lectularius L., the common bed bug from pharaonic Egypt. Antiquity. 1999;73(282):908-11.

6. Kolb A, Needham GR, Neyman KM, High WA. Bedbugs. Dermatol Ther. 2009;22(4):347-52.

7. Busvine JR. Insecticide-resistance in bed-bugs. Bull World Health Organ. 1958;19(6):1041-52.

8. Mueller G, Luescher IL, Schmidt M. Temporal changes in the incidence of household arthropod pests in Zurich, Switzerland. In: Robinson WH, Bajomi D, editors. Proceedings of the Sixth International Conference on Urban Pests. Veszprém: OOK-Press Kft.; 2008. p. 15-21.
9. Mumcuoglu KY. A case of imported bedbug (Cimex lectularius) infestation in Israel. Isr Med Assoc J. 2008 May;10(5):388-9.

10. Romero A, Potter MF, Potter DA, Haynes KF. Insecticide resistance in the bed bug: a factor in the pest's sudden resurgence? J Med Entomol. 2007;22(2):175-8.

11. Potter MF, Haynes KF, Fredericks J. Bed bugs across America. Pestworld [Internet]. 2015 [cited 2018 Dec 3];(Nov-Dec):4-14. Available from: https://www.npmapestworld.org/default/assets/File/newsroom/ magazine/2015/nov-dec_2015.pdf.

12. Doggett SL. Bed bug survey-are we biting back? Profes Pest Manag [Internet]. 2016 [cited 2018 Dec 3];(Aug-Sep):28-30. Available from: http://www.ppmmagazine.com.au/magazine/enterId/forward_action/ $\mathrm{read} / \mathrm{id} / 290$.

13. Li S, Gouge DH, Fournier A, Stock T, Romero A, Young D, et al. Life quality impacts of bed bug (Cimex lectularius L.) infestations. In: XXV International Congress of Entomology; 2016 Sep 25-29; Orlando, FL.

14. Wang, C, Eiden, A, Singh, N, Zha, C, Wang, D, Cooper, R. Dynamics of bed bug infestations in three low-income housing communities with various bed bug management programs. Pest Manag Sci. 2018;74(6):1302-10.

15. Romero A, Sutherland AM, Gouge DH, Spafford H, Nair S, Lewis V, et al. Pest management strategies for bed bugs (Hemiptera: Cimicidae) in multiunit housing: A literature review on field studies. J Integr Pest Manag. 2017;8(1):13. doi: 10.1093/jipm/pmx009.

16. Hwang SW, Svoboda TJ, De Jong IJ, Kabasele KJ, Gogosis E. Bed bug infestations in an urban environment. Emerg Infect Dis. 2005;11(4):533-8.

17. Wang C, Singh N, Zha C, Cooper R. Bed bugs prevalence in low incoms communites. J Med Entomol. 2016;53(3):639-46.

18. Temu EA, Minjas JN, Shiff CJ, Majala A. Bedbug control by permethrinimpregnated bednets in Tanzania. Med Vet Entomol. 1999;13(4):457-9.

19. Boase C. Bedbugs-back from the brink. Pesticide Outlook. 2001;12(4):15962.

20. Hungarian Central Statistical Office [Internet]. [cited 2016 Oct 14]. Available from: http://www.ksh.hu/?lang=en.

21. Haylock MR, Hofstra N, Klein Tank AMG, Klok EJ, Jones PD, New M. A European daily high-resolution gridded data set of surface temperature and precipitation for 1950-2006. J Geophys Res Atmos. 2008;113(D20):D20119. doi: 10.1029/2008JD010201.

22. Lowry R. VassarStats: website for statistical computation [Internet]. Vassar College; 2004 [cited 2018 Dec 3]. Available from: http://vassarstats. net/.

23. Wessa P. Free statistics software version 1.1. 23-r1 [Internet]. 2008 [cited 2018 Dec 3]. Available from: https://www.wessa.net/.

24. Statstutor [Internet]. Loughborough: Mathematics Education Centre, Loughborough University, UK [cited 2016 Oct 14]. Available from: http://www.statstutor.ac.uk/contact/.

25. Hwang SW, Svoboda TJ, de Jong IJ, Kabasele KJ, Gogosis E. Bed bug infestations in an urban environment. Emerg Infect Dis. 2005;11(4):533-8.

26. Potter MF. The perfect storm: an extension view on bed bugs. Am Entomol. 2006;52(2):102-4.

27. Dogett SL, Miller DM, Lee CY, editors. Advances in the biology and management of modern bed bugs. Wiley Blackwell; 2018.

28. Alalawi AH. Bed bugs epidemic in the United States. Entomol Ornithol Herpetol. 2014;4(1):143. doi: 10.4172/2161-0983.1000143.

29. Mabud TS, Barbarin AM, Barbu CM, Levy KH, Edinger J, Levy MZ. Spatial and temporal patterns in Cimex lectularius (Hemiptera: Cimicidae) reporting in Philadelphia, PA. J Med Entomol. 2014;51(1):50-4.

30. Cooper R, Wang C, Singh N. Mark-release-recapture reveals extensive movement of bed bugs (Cimex lectularius L.) within and between apartments. PloS One. 2015;10(9):e0136462. doi: 10.1371/journal. pone. 0136462 . 